\title{
Exposure to vector-borne pathogens in candidate blood donor and free-roaming dogs of northeast Italy
}

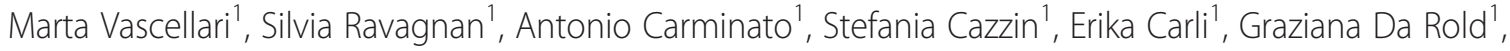 \\ Laura Lucchese ${ }^{1}$, Alda Natale ${ }^{1}$, Domenico Otranto ${ }^{2}$ and Gioia Capelli $i^{*}$
}

\begin{abstract}
Background: Many vector-borne pathogens including viruses, bacteria, protozoa and nematodes occur in northeast Italy, representing a potential threat to animal and human populations. Little information is available on the circulation of the above vector-borne pathogens in dogs. This work aims to (i) assess exposure to and circulation of pathogens transmitted to dogs in northeast Italy by ticks, sandflies, and mosquitoes, and (ii) drive blood donor screening at the newly established canine blood bank of the Istituto Zooprofilattico Sperimentale delle Venezie.
\end{abstract}

Methods: Blood samples from 150 privately-owned canine candidate blood donors and 338 free-roaming dogs were screened by serology (IFA for Leishmania infantum, Ehrlichia canis, Anaplasma phagocythophilum, Babesia canis, Rickettsia conorii, R. rickettsii), microscopic blood smear examination, and blood filtration for Dirofilaria spp. All candidate donors and seropositive free-roaming dogs were tested by PCR for L. infantum, E. canis, A. phagocythophilum, Babesia/Theileria and Rickettsia spp. The dogs had no clinical signs at the time of sampling.

Results: Overall, 40 candidate donors (26.7 \%) and 108 free-roaming dogs (32\%) were seroreactive to at least one vector-borne pathogen. Seroprevalence in candidate donors vs free-roaming dogs was: Leishmania infantum 6.7 vs 7.1 \%; Anaplasma phagocytophilum 4.7 vs 3.3 \%; Babesia canis 1.3 vs $2.7 \%$; Ehrlichia canis none vs 0.9 \%; Rickettsia conorii 16 vs $21.3 \%$ and $R$. rickettsii 11 vs $14.3 \%$. Seroreactivity to $R$. rickettsii, which is not reported in Italy, is likely a cross-reaction with other rickettsiae. Filariae, as Dirofilaria immitis $(n=19)$ and D. repens $(n=2)$, were identified in free-roaming dogs only. No significant differences were observed between candidate donors and free-roaming dogs either in the overall seroprevalence of vector-borne pathogens or for each individual pathogen. All PCRs and smears performed on blood were negative.

Conclusions: This study demonstrated that dogs are considerably exposed to vector-borne pathogens in northeast Italy. Although the dog owners reported regularly using ectoparasiticides against fleas and ticks, their dogs had similar exposure to vector-borne pathogens as free-roaming dogs. This prompts the need to improve owner education on the use of insecticidal and repellent compounds in order to reduce the risk of arthropod bites and exposure to vector-borne pathogens. Based on the absence of pathogens circulating in the blood of healthy dogs, the risk of transmission of these pathogens by blood transfusion seems to be low, depending also on the sensitivity of the tests used for screening.

Keywords: Vector-borne pathogens, Canine blood donors, Free-roaming dogs, Exposure, IFAT, Real-time PCR, Italy

\footnotetext{
* Correspondence: gcapelli@izsvenezie.it

${ }^{1}$ Istituto Zooprofilattico Sperimentale delle Venezie, Legnaro, Padova, Italy

Full list of author information is available at the end of the article
} 


\section{Background}

Several vector-borne pathogens (VBPs), transmitted by ticks, mosquitoes and sandflies, occur in dogs living in northeast Italy. Infection and/or disease are caused by members of the genera Anaplasma, Babesia, Borrelia, Dirofilaria, Ehrlichia, Leishmania, and Rickettsia [1-7]. Some of these infections can be life-threatening in dogs (leishmaniosis, cardiopulmonary filariosis, babesiosis) and, in some cases, in humans (leishmaniosis, dirofilariosis, anaplasmosis) [6].

The occurrence of a VBP in a given area is directly dependent on the presence of reservoir hosts and the density of the vectors. For example, the distribution of arthropod vectors in northeast Italy is well known as regards mosquitoes due to the presence of surveillance programs for West Nile virus $[8,9]$ and other arboviruses transmitted by the tiger mosquitoes, Aedes albopictus [10, 11]. Culex pipiens, Ae. albopictus, Ochlerotatus caspius and $A e$. vexans have been identified as the most widespread mosquitoes in the area, including the novel invasive species, Aedes koreicus, which has recently been detected [12] and is expanding [13, 14]. All of the above mosquito species have been proven or are suspected to be vectors of Dirofilaria spp. [15-18].

Ixodes ricinus is the most widespread tick species in northeast Italy and has repeatedly been found to be infected with VBPs that can also affect dogs, i.e. Borrelia burgdorferi (s.l.), Rickettsia helvetica, R. monacensis, Anaplasma phagocytophilum, Candidatus Neoehrlichia mikurensis, Babesia spp. [19-24]. However, the most common tick species removed from dogs of north Italy is Rhipicephalus sanguineus, followed by I. hexagonus, I. ricinus and Dermacentor marginatus [21, 25, 26]. No studies are available on the vectorial role of $R h$. sanguineus in north Italy.

Two species of sandfly, Phlebotomus perniciosus and $P$. neglectus, have been reported in northeast Italy [4, 27, 28 ], where they are probably responsible for the transmission of L. infantum to dogs.

Several VBPs can also be transmitted by blood transfusion. The safety of donated blood with respect to VBPs is guaranteed by serological and molecular screening of dog donors. The Consensus Statements of the American College of Veterinary Internal Medicine (ACVIM) for blood transfusion [29] recommend that donors be screened for VBPs in accordance with the following criteria: (i) the agent is known to be present in the territory; (ii) the agent is known to be potentially transmitted by blood transfusion; (iii) the agent is capable of causing subclinical infection in candidate blood donors; (iv) the disease in the recipient is severe or difficult to foresee. Hence knowledge of VBP circulation among dog populations is pivotal to estimating the risk of transmission by transfusion.
In this study, we assessed exposure to and circulation of pathogens transmitted by ticks, sandflies and mosquitoes to dogs in northeast Italy, including freeroaming dogs and candidate blood donors at the newly established canine Blood Bank of the Istituto Zooprofilattico Sperimentale delle Venezie.

\section{Methods \\ Dogs}

From January 2014 to December 2015, a total of 488 dogs, including candidate blood donors (CBD) $(n=150)$ and free-roaming dogs (FRD) $(n=338)$, were sampled in several municipalities of the provinces of north and northeast Italy (municipalities of Padua, Treviso, Verona, Venice, Milan and Bologna).

The breed, age, gender and location of the dogs are reported in Table 6.

CBDs were privately-owned dogs and included animals $(n=41)$ from two dog breeders. According to Italian Ministry of Health guidelines (http://tinyurl.com/h7vs3lz), candidate donor dogs need to fulfil the following inclusion criteria: age $2-8$ years, body weight $\geq 25 \mathrm{~kg}$, clinically healthy, regularly vaccinated and protected against endo- and ectoparasites.

The FRDs included dogs with no identification (microchip) and privately-owned dogs allowed to wander around, especially in peri-urban and rural areas. According to the Italian law on Companion Animals and the Prevention of Stray Animals (Act no. 281/1991), FRDs are captured by the Local Veterinary Service, housed in shelters and sampled soon after capture. Conversely, CBDs were sampled at their first clinical visit. Whole blood and sera were tested by serology, PCR, blood smear examination, and blood filtration.

\section{Ethical statement}

Informed consent was obtained from the owners of CBDs, as required by the Blood Bank to become eligible donors. The donor screening programme included the collection of information on the health history of the dogs and infectious disease testing. FRDs were sampled and underwent a clinical evaluation by the Local Veterinary Health units at the time of entry to the shelter, as part of the zoonotic agent control programme.

\section{Diagnostic procedures \\ Serology}

Dog sera were tested by means of indirect immunofluorescence assay (IFA) to detect and quantify IgG antibodies against L. infantum, E. canis, A. phagocythophilum, B. canis, $R$. conorii and $R$. rickettsii. The latter pathogen is not reported in the Old World but was included in the screening battery in an attempt to detect cross-reactions with rickettsiae other than $R$. conorii. The in-house assay 
for $L$. infantum was performed according to the procedure described in the OIE Terrestrial Manual [30]. The serum screening dilution was set at 1:40.

The detection of IgG antibodies against the other pathogens was carried out using commercial kits following the manufacturers' instructions. The kits were: the Ehrlichia canis Canine IFA IgG Kit (Fuller Laboratories, Fullerton, California, USA), serum screening dilution 1:50; the Canine Granulocytic Anaplasmosis IgG IFA Kit (Fuller Laboratories, Fullerton, California, USA), serum screening dilution 1:80; Fluo Babesia canis (Agrolabo S.p.A., Scarmagno, Italy), serum screening dilution 1:16; the Rickettsia conorii Canine IFA IgG Kit, and the Rickettsia rickettsii Canine IFA IgG Kit (Fuller Laboratories, Fullerton, California, USA), serum screening dilution 1:64. Positive and negative controls were added to each slide of the in-house and commercial kits. Two-fold serial dilutions were prepared and tested to define the serum titre of samples testing positive at screening.

\section{Molecular analyses}

DNA was extracted from EDTA-blood samples using a DNeasy Blood \& Tissue kit (Qiagen, Valencia, CA, USA), according to the manufacturer's instructions. The samples were screened for Babesia/Theileria spp., Rickettsia spp., Leishmania spp. and Ehrlichia canis, using in-house SYBR Green Real-Time PCR (rPCR) assays, performed with the primers from [31-34] (Table 1). The reactions were carried out in a total volume of $20 \mu \mathrm{l}$, containing $10 \mu \mathrm{l}$ of QuantiFast SYBR Green PCR Master mix 2X (Qiagen GmbH, Germany), sense and reverse primer (concentration reported in Table 1) and $3 \mu \mathrm{l}$ of extracted DNA. Amplifications were performed in a StepOnePlus ${ }^{\text {TM }}$ instrument (Applied Biosystems, Foster City, CA). The thermal profile consisted of 5 min of activation at $95{ }^{\circ} \mathrm{C}$, followed by 40 cycles at $95{ }^{\circ} \mathrm{C}$ for $15 \mathrm{~s}$ (denaturation), specific annealing temperature (Table 1) for $30 \mathrm{~s}$ (annealing) and $60{ }^{\circ} \mathrm{C}$ for $30 \mathrm{~s}$ (extension). Following amplification, a melting curve analysis was performed by slowly raising the temperature of the thermal chamber from $60^{\circ} \mathrm{C}$ to $95{ }^{\circ} \mathrm{C}$ to distinguish between specific amplicons and non-specific amplification products. Anaplasma phagocytophilum DNA was amplified by conventional PCR targeting the major surface protein gene (msp2), as described elsewhere [35]. To ensure the effectiveness of the nucleic acid extraction, a PCR targeting the 18S rRNA gene internal control was applied [36]. Negative (sterile water) and positive controls (DNA of Theileria orientalis, Rickettsia felis, Leishmania infantum, Ehrlichia canis and Anaplasma phagocytophilum) were included in each run.

\section{Blood smear examination}

The blood smears were stained (Diff Quick Stain Set, Medion Diagnostic AG, Duedingen, SZ) and examined for the presence of any pathogens, i.e. L. infantum, Babesia spp., Hepatozoon canis, A. phagocytophilum, A. platys, E. canis and microfilariae.

\section{Filariae screening and identification}

One $\mathrm{ml}$ of blood in ethylene diamine tetraacetic acid (EDTA) was tested by standard filtration test and staining. The number of microfilariae per millilitre $(\mathrm{mf} / \mathrm{ml})$ was calculated as the average of ten counts serially performed on $10 \mu \mathrm{l}$ of blood samples. The identification of microfilariae was based on their morphology and morphometry [37]. The samples suspected to be positive for $D$. repens were confirmed by PCR and sequencing [38].

\section{Statistical analysis}

The differences between CBDs and FRDs in the prevalence of VBPs for each pathogen and each data element collected on the dogs (breed, gender, age and location) were analysed by the Chi-square test or Fisher's exact test, where appropriate. Significance was set at $P<0.01$. The agreement between serological status for $R$. conorii/R. rickettsii and for $A$. phagocytophilum/E. canis was tested

Table 1 Target genes and rPCR primers used in this study for pathogen identification

\begin{tabular}{|c|c|c|c|c|c|c|}
\hline Target organism & Gene & Primer & Sequence $\left(5^{\prime}-3^{\prime}\right)$ & $\begin{array}{l}\mathrm{PC} \\
(\mu \mathrm{M})\end{array}$ & $\begin{array}{l}\text { TA } \\
\left({ }^{\circ} \mathrm{C}\right)\end{array}$ & $\overline{\text { Reference }}$ \\
\hline \multirow[t]{2}{*}{ Babesia/Theileria } & $18 \mathrm{~S}$ rRNA & BJ1 & GTCTTGTAATTGGAATGATGG & 0.1 & 60 & [31] \\
\hline & & BN2 & TAGTTTATGGTTAGGACTACG & 0.1 & & \\
\hline \multirow[t]{2}{*}{ Rickettsia spp. } & rompB & RompB OFm & GTAACCGGAARTAATCGTTTCGT & 0.1 & 58 & [32] \\
\hline & & RompB ORm & GCTITATAACCAGCTAAACCRCC & 0.1 & & \\
\hline \multirow[t]{2}{*}{ Leishmania spp. } & COII & COII F & GGCATAAATCCATGTAAGA & 0.3 & 52 & [33] \\
\hline & & COII R & TGGCTITTATATTATCATTIT & 0.3 & & \\
\hline \multirow[t]{2}{*}{ Ehrlichia canis } & $16 \mathrm{~S}$ rRNA & CANIS & CAATTATTTATAGCCTCTGGCTATAGGA & 0.5 & 60 & [34] \\
\hline & & CA1UR & GAGTTTGCCGGGACTTCTTCT & 0.5 & & \\
\hline
\end{tabular}

Abbreviations: $T A$ temperature of annealing; Pc primer concentration

$16 \mathrm{~S}$ rRNA = gene coding $16 \mathrm{~S}$ ribosomal RNA; rompB = Rickettsial Outer Membrane Protein B gene; COII = Cytochrome $c$ oxidase subunit II gene ; 18S rRNA = gene coding $18 \mathrm{~S}$ ribosomal RNA 
using the kappa coefficient [39]. SPSS for Windows, version 13.0 software was used.

\section{Results}

None of the dogs had any clinical signs of VBDs at the time of sampling. The owners of CBDs reported regularly using compounds to control fleas and ticks and taking preventative measures against filariae, while no information was available for FRDs.

Overall, 40 CBDs (26.7 \%) and 108 FRDs (32.0 \%) were seroreactive to at least one VBP, as shown in Table 2. No significant differences were observed between CBDs and FRDs in the overall seroprevalence of VBPs or for each individual pathogen.

Seropositivity was most frequently detected against rickettsiae (26\% in CBDs vs $24.3 \%$ in FRDs), followed by $L$. infantum ( $7 \%$ in both groups).

Twenty-six of the CBDs (17.3\%) were seroreactive to one test only, $13(8.7 \%)$ to two and $1(0.7 \%)$ to three (details in Table 3). Of the FRDs, 56 dogs (16.6 \%) were seroreactive to one test only, $43(12.7 \%)$ to two, 7 $(2.1 \%)$ to three and $1(0.3 \%)$ to four (details in Table 4$)$.

The most common seropositivity for two antigens in the same $\operatorname{dog}$ (co-reaction) was for $R$. conorii and $R$. rickettsii, in both groups of dogs (Tables 3 and 4). Specifically, of the 101 dogs testing positive for Rickettsia spp., 49 (48.5\%) were positive for both rickettsiae, 41 (40.6\%) exclusively for $R$. conorii and 11 (10.9 \%) exclusively for $R$. rickettsii, the latter all being FRDs. Agreement between seropositivity for the two rickettsiae was moderate $(k=0.586)$, suggesting a certain degree of cross-reactivity. Conversely, seroreactivity for A. phagocytophilum and E. canis was completely discordant $(\mathrm{k}=-0.29)$, suggesting that these antigens did not cross-react in our test.

The distribution of antibody titres was similar between CBDs and FRDs $(P>0.05)$ (Table 5).

Among the dogs testing positive for L. infantum, only one dog showed a high antibody titre, consistent with clinical leishmaniosis (1:1280). The antibody titre for $R$. conorii or $R$. rickettsii was above 1: 320 (Table 5) in a total of 26 dogs (5.3\%). The 12 CBDs testing positive to both species of Rickettsia showed very similar titres. Conversely, 10 (27\%) of the 37 FRDs presenting coreactions had a higher titre for $R$. rickettsii.

No significant differences were found between seropositivity and the data given in Table 6 .

Microfilariae were found exclusively in FRDs $(n=21$; 6.4\%) $\left(\chi^{2}=9.982, d f=1, P=0.0016\right)$ and were identified as $D$. immitis $(n=19)$ and $D$. repens $(n=2)$. All dogs testing positive for microfilariae were from the province of Padua (21/219; $9.6 \%)$. The microfilariae of $D$. immitis per $\mathrm{ml}$ of blood $(\mathrm{mf} / \mathrm{ml})$ ranged from 4 to 26,620 (mean = 413), and numbered 26 and 14,440 mf/ml, respectively, in the two dogs found positive for $D$. repens.

All PCRs and smears performed on blood were negative.

\section{Discussion}

This study has demonstrated that dogs are considerably exposed to VBPs in northeast Italy. The most frequent pathogens encountered by dogs in this area are members of the genus Rickettsia. Considering that $R$. rickettsii (the agent of Rocky Mountain Spotted Fever) is not reported in the Old World, the seroreactivity to this pathogen in the dogs in our study was the effect of a cross-reaction with other rickettsiae, as reported elsewhere [41] and stated in the instructions accompanying the serological kit used. The following species of Rickettsia were detected in north Italy: $R$. helvetica and $R$. monacensis, a common finding in Ixodes ricinus ticks [19, 20, 24], and $R$. slovaca and $R$. raoultii, detected in Dermacentor marginatus ticks removed from wild boars [42]. The circulation of many other Rickettsia spp. is reported in hosts and vectors in central and southern Italy, the most common being $R$. massiliae, $R$. aeschlimannii and $R$. conorii israeliensis [25, 43, 44].

Rickettsia conorii (the agent of the Mediterranean Spotted Fever), has been detected almost exclusively in southern Italy, in both humans [40] and dogs [2]. It can therefore be argued that a certain level of seroreactivity

Table 2 Serological results and positivity for filariae in candidate blood donors and free-roaming dogs of northeastern Italy, 2014-2015

\begin{tabular}{|c|c|c|c|c|c|c|}
\hline \multirow[t]{2}{*}{ Pathogens } & \multicolumn{3}{|c|}{ Candidate blood donors } & \multicolumn{3}{|c|}{ Free-roaming dogs } \\
\hline & No. examined & No. positive & $\%$ & No. examined & No. positive & $\%$ \\
\hline Anaplasma phagocytophilum & 150 & 7 & 4.7 & 338 & 11 & 3.3 \\
\hline Babesia canis & 104 & 0 & 0 & 338 & 3 & 0.9 \\
\hline Ehrlichia canis & 150 & 2 & 1.3 & 338 & 9 & 2.7 \\
\hline Leishmania infantum & 150 & 10 & 6.7 & 336 & 24 & 7.1 \\
\hline Rickettsia conorii & 150 & 24 & 16.0 & 338 & 72 & 21.3 \\
\hline Rickettsia rickettsii & 109 & 12 & 11.0 & 336 & 48 & 14.3 \\
\hline R. conorii and $R$. rickettsii & 109 & 12 & 11.0 & 336 & 33 & 9.82 \\
\hline Dirofilaria spp. & 150 & 0 & 0 & 330 & 21 & 6.4 \\
\hline
\end{tabular}


Table 3 Candidate blood donors seroreactive to several antigens $(n=40)$

\begin{tabular}{|c|c|c|c|c|c|c|}
\hline Candidate donor no. & $A p$ & $B C$ & EC & $\mathrm{Li}$ & $R c$ & $R r$ \\
\hline 1 & 0 & ne & 0 & $1: 40$ & 0 & ne \\
\hline 2 & 0 & 0 & 0 & $1: 40$ & $1: 64$ & 0 \\
\hline 3 & $1: 80$ & 0 & 0 & 0 & 0 & 0 \\
\hline 4 & 0 & 0 & 0 & $1: 80$ & 0 & 0 \\
\hline 5 & $1: 80$ & 0 & 0 & 0 & 0 & 0 \\
\hline 6 & 0 & 0 & 0 & 0 & $1: 64$ & 0 \\
\hline 7 & 0 & ne & 0 & $1: 40$ & 0 & ne \\
\hline 8 & $1: 160$ & 0 & 0 & 0 & 0 & 0 \\
\hline 9 & $1: 160$ & 0 & 0 & 0 & 0 & 0 \\
\hline 10 & 0 & ne & 0 & 0 & $1: 64$ & ne \\
\hline 11 & $1: 80$ & ne & 0 & 0 & 0 & ne \\
\hline 12 & 0 & ne & 0 & 0 & $1: 512$ & ne \\
\hline 13 & 0 & 0 & 0 & 0 & $1: 128$ & 0 \\
\hline 14 & 0 & 0 & 0 & 0 & $1: 64$ & $1: 64$ \\
\hline 15 & $1: 80$ & 0 & 0 & 0 & $1: 512$ & $1: 512$ \\
\hline 16 & 0 & 0 & 0 & 0 & $1: 128$ & 0 \\
\hline 17 & 0 & 0 & 0 & 0 & $1: 64$ & $1: 64$ \\
\hline 18 & 0 & ne & 0 & $1: 40$ & 0 & 0 \\
\hline 19 & 0 & ne & 0 & 0 & $1: 64$ & ne \\
\hline 20 & 0 & 0 & 0 & 0 & $1: 256$ & $1: 256$ \\
\hline 21 & 0 & 0 & 0 & 0 & $1: 64$ & $1: 64$ \\
\hline 22 & 0 & ne & 0 & $1: 40$ & 0 & ne \\
\hline 23 & 0 & ne & 0 & $1: 40$ & 0 & ne \\
\hline 24 & 0 & ne & 0 & $1: 40$ & 0 & ne \\
\hline 25 & 0 & 0 & 0 & $1: 1280$ & $1: 256$ & 0 \\
\hline 26 & 0 & ne & 0 & 0 & $1: 256$ & ne \\
\hline 27 & 0 & 0 & 0 & 0 & $1: 64$ & $1: 64$ \\
\hline 28 & 0 & 0 & 0 & 0 & $1: 64$ & 0 \\
\hline 29 & 0 & 0 & 0 & 0 & $1: 64$ & 0 \\
\hline 30 & 0 & 0 & 0 & 0 & $1: 64$ & $1: 64$ \\
\hline 31 & 0 & 0 & 0 & 0 & $1: 64$ & $1: 64$ \\
\hline 32 & 0 & 0 & 0 & 0 & $1: 8192$ & $1: 2048$ \\
\hline 33 & 0 & 0 & 0 & 0 & $1: 64$ & $1: 64$ \\
\hline 34 & 0 & 0 & $1: 80$ & 0 & 0 & 0 \\
\hline 35 & 0 & ne & 1:50 & 0 & 0 & ne \\
\hline 36 & 0 & 0 & 0 & 0 & $1: 64$ & 0 \\
\hline 37 & 0 & 0 & 0 & 0 & $1: 128$ & $1: 128$ \\
\hline 38 & 0 & ne & 0 & $1: 40$ & 0 & ne \\
\hline 39 & $1: 80$ & 0 & 0 & 0 & 0 & 0 \\
\hline 40 & 0 & 0 & 0 & 0 & $1: 128$ & $1: 256$ \\
\hline
\end{tabular}

Abbreviations: Ap, Anaplasma phagocytophilum; Bc, Babesia canis; Ec, Ehrlichia canis; Li, Leishmania infantum; Rc, Rickettsia conorii; Rr, Rickettsia rickettsii; ne, not examined to this antigen is due to a cross-reaction with other Rickettsia spp.

The high rate of exposure to rickettsiae and the low rate of exposure to $A$. phagocytophilum of the dogs in our study is consistent with the rate of infection found in Ixodes ricinus in the same area between 2005 and 2008 (i.e. $13.1 \%$ and $3.7 \%$ for $R$. helvetica and $R$. monacensis, respectively, and $1.5 \%$ for A. phagocytophilum) [24].

In our survey, three FRDs had high titres for A. phagocytophilum, without any evident clinical signs, indicating either a previous infection or a subclinical/ mild infection in dogs not subjected to laboratory testing to carefully evaluate their clinical status. However, in a previous study using an IFA test, seroprevalence was not significantly different between sick (47 \%) and healthy dogs (40\%) [45].

Our dogs were found to have a very low rate of exposure to other pathogens transmitted by Rhipicephalus ticks (Ehrlichia and Babesia) compared to studies performed in central [46] and southern Italy [47, 48], which reported seroprevalence to be up to $46 \%$ for E. canis and as high as $70 \%$ for Babesia spp. This is likely due to the lower abundance of the brown dog tick of the $R h$. sanguineus group in the northern compared to southern Italy, where warmer temperatures throughout the year may contribute to increasing tick abundance [49].

In addition, many studies have suggested that vector competence of different populations (haplotypes or sibling species) of the $R$. sanguineus group may vary, reviewed in [50]. However, populations of $R$. sanguineus have never been accurately mapped in northern Italy.

The second pathogen to which FRDs and CBD dogs are exposed is L. infantum. All but one of the animals showed a serological titre below 1:80, a cut-off not usually indicative of infection [51] and thus requiring confirmation by other tests or seroconversion. The IFA used in this study showed no [52], or a very low rate of, cross-reaction with other VBPs [53], suggesting that the seroreactivity is most likely due to contact with an infected sandfly.

This is consistent with the history of Leishmania in northern regions. Indeed, 20 years ago canine leishmaniosis was regarded as an infection "imported" from endemic areas of the south. The scenario has quickly changed [5], with new foci continuing to emerge in northern regions $[4,54,55]$ and phlebotomine vectors recently being found in the northernmost part of the eastern Italian Alps [27].

Detection of $D$. immitis and D. repens in FRDs indicate that both nematodes are still circulating in the area of investigation, particularly in the lowlands around Padua. Northeastern Italy is an endemic area for D. immitis, with prevalences of up to $80 \%$ being reported in the past $[5,56]$. Surveys performed in the 1990s in the same province found $67 \%$ of 175 stray dogs at the local 
Table 4 Free-roaming dogs seroreactive to several antigens $(n=108)$

\begin{tabular}{|c|c|c|c|c|c|c|}
\hline Free-roaming dog no. & $A p$ & $B C$ & $E C$ & $\mathrm{Li}$ & $R c$ & $R r$ \\
\hline 1 & 0 & 0 & 0 & 0 & $1: 128$ & $1: 128$ \\
\hline 2 & 0 & 0 & 0 & 0 & $1: 64$ & 0 \\
\hline 3 & 0 & 0 & 0 & $1: 40$ & 0 & 0 \\
\hline 4 & 0 & 0 & 0 & 0 & 1:128 & $1: 128$ \\
\hline 5 & 0 & 0 & 0 & 0 & $1: 128$ & 0 \\
\hline 6 & 0 & 0 & 1:50 & 0 & 0 & 0 \\
\hline 7 & 0 & 0 & $1: 50$ & 0 & 0 & 0 \\
\hline 8 & 0 & 0 & 0 & 0 & $1: 64$ & 0 \\
\hline 9 & 0 & 0 & 0 & 0 & $1: 256$ & $1: 256$ \\
\hline 10 & 0 & 0 & 0 & 0 & $1: 64$ & 0 \\
\hline 11 & 0 & 0 & $1: 50$ & 0 & 0 & 0 \\
\hline 12 & 0 & 0 & $1: 50$ & 0 & 1:128 & 0 \\
\hline 13 & 0 & 0 & 0 & 0 & $1: 64$ & 0 \\
\hline 14 & 0 & 0 & 0 & 0 & 1:128 & 0 \\
\hline 15 & 0 & 0 & 0 & 0 & 1:128 & 0 \\
\hline 16 & 0 & 0 & 0 & 0 & $1: 64$ & 0 \\
\hline 17 & 0 & 0 & 0 & 0 & $1: 512$ & 1:128 \\
\hline 18 & 0 & 0 & 0 & $1: 40$ & $1: 128$ & 0 \\
\hline 19 & 0 & 0 & 0 & $1: 40$ & $1: 256$ & 0 \\
\hline 20 & 0 & 0 & 0 & 0 & 0 & $1: 64$ \\
\hline 21 & 0 & 0 & 0 & 0 & $1: 64$ & 0 \\
\hline 22 & 0 & 0 & 0 & 0 & 1:128 & 0 \\
\hline 23 & 0 & 0 & 1:50 & 0 & 0 & 0 \\
\hline 24 & 0 & 0 & 0 & 0 & 0 & $1: 64$ \\
\hline 25 & 0 & 0 & 0 & 0 & $1: 64$ & $1: 64$ \\
\hline 26 & 0 & 0 & 0 & 0 & $1: 64$ & $1: 64$ \\
\hline 27 & 0 & 0 & 0 & 0 & $1: 64$ & 0 \\
\hline 28 & 0 & 0 & 0 & 0 & $1: 64$ & $1: 64$ \\
\hline 29 & 0 & 0 & $1: 50$ & 0 & $1: 64$ & $1: 64$ \\
\hline 30 & 0 & 0 & 1:400 & 0 & 0 & 0 \\
\hline 31 & 0 & 0 & 0 & 0 & $1: 512$ & $1: 256$ \\
\hline 32 & 0 & 0 & 0 & 0 & $1: 2048$ & 1:2048 \\
\hline 33 & $1: 80$ & 0 & 0 & $1: 40$ & $1: 1024$ & $1: 512$ \\
\hline 34 & 0 & 0 & 0 & $1: 40$ & 0 & 0 \\
\hline 35 & 0 & 0 & 0 & $1: 40$ & $1: 64$ & 0 \\
\hline 36 & 0 & 0 & 0 & 0 & $1: 128$ & 0 \\
\hline 37 & 0 & 0 & 0 & 0 & $1: 128$ & 1:128 \\
\hline 38 & 0 & 0 & 0 & $1: 40$ & $1: 1024$ & $1: 256$ \\
\hline 39 & $1: 80$ & 0 & 0 & $1: 40$ & 0 & 0 \\
\hline 40 & 0 & 0 & 0 & 0 & $1: 64$ & 0 \\
\hline 41 & 0 & 0 & 0 & 0 & $1: 128$ & 0 \\
\hline 42 & 0 & 0 & 0 & 0 & $1: 128$ & 0 \\
\hline 43 & 0 & 0 & 0 & 0 & $1: 64$ & 0 \\
\hline
\end{tabular}

Table 4 Free-roaming dogs seroreactive to several antigens $(n=108)$ (Continued) 
Table 4 Free-roaming dogs seroreactive to several antigens $(n=108)$ (Continued)

\begin{tabular}{lllllll}
\hline Free-roaming dog no. & $A p$ & $B C$ & $E C$ & $L i$ & $R c$ & $R r$ \\
\hline 87 & 0 & 0 & 0 & 0 & 0 & $1: 128$ \\
88 & 0 & 0 & 0 & 0 & $1: 256$ & $1: 128$ \\
89 & 0 & 0 & 0 & 0 & 0 & $1: 64$ \\
90 & 0 & 0 & 0 & 0 & $1: 128$ & $1: 128$ \\
91 & 0 & 0 & $1: 50$ & 0 & 0 & 0 \\
92 & 0 & 0 & 0 & 0 & $1: 64$ & $1: 256$ \\
93 & 0 & 0 & $1: 100$ & 0 & 0 & 0 \\
94 & 0 & 0 & 0 & 0 & 0 & $1: 64$ \\
95 & 0 & 0 & 0 & 0 & 0 & $1: 64$ \\
96 & $1: 5120$ & 0 & 0 & 0 & 0 & 0 \\
97 & 0 & 0 & 0 & 0 & $1: 512$ & $1: 1024$ \\
98 & 0 & 0 & 0 & $1: 40$ & 0 & 0 \\
99 & 0 & $1: 16$ & 0 & 0 & 0 & 0 \\
100 & 0 & $1: 16$ & 0 & 0 & 0 & 0 \\
101 & 0 & 0 & 0 & $1: 40$ & 0 & 0 \\
102 & 0 & 0 & 0 & 0 & $1: 64$ & $1: 64$ \\
103 & 0 & 0 & 0 & 0 & $1: 64$ & $1: 256$ \\
104 & 0 & 0 & 0 & 0 & $1: 64$ & $1: 128$ \\
105 & 0 & 0 & 0 & $1: 40$ & 0 & 0 \\
106 & 0 & 0 & 0 & 0 & $1: 128$ & $1: 128$ \\
107 & 0 & 0 & 0 & $1: 64$ & $1: 64$ \\
108 & 0 & 0 & $1: 40$ & 0 & 0 \\
\hline$A 66 r$ & 0 & 0 & 0 & 0
\end{tabular}

Abbreviations: Ap, Anaplasma phagocytophilum; Bc, Babesia canis; Ec, Ehrlichia canis; Li, Leishmania infantum; Rc, Rickettsia conorii; Rr, Rickettsia rickettsii; ne, not examined

municipality shelter to be infected by $D$. immitis [57]. At the end of the 1990s, contact between a mosquito infected by $D$. immitis and a host was estimated to occur every four nights for dogs and within two weeks for humans [7]. In subsequent years, after the advent of efficient preventative measures, the prevalence of heartworm infection dramatically decreased, especially in urban areas (unpublished data). However, in rural areas, both $D$. immitis and $D$. repens are still circulating, as demonstrated by the positivity of the FRDs taking part in this study and the presence of infected mosquitoes. The screening in 2010 of over 10,000 mosquitoes captured in the same area as this study revealed the presence of $D$. immitis, alone or in combination with $D$. repens, in 13 and two of the 20 monitored sites, respectively [17].

Despite the considerable rate of exposure to VBPs, none of the study dogs presented evident clinical signs and/or circulating pathogens at the time of sampling. This is not surprising, since the detection of pathogens in the bloodstream can be difficult even in clinical cases [1, 2, 41, 59-61]. A study performed on 650 sick dogs, yielded positive PCR results for Rickettsia spp. in 0.4, 1.4 and $3.3 \%$ of dogs from northern, central and southern Italy, respectively [2]. Another study was unable to find A. phagocytophilum and Rickettsia spp. in 135 sick Italian dogs and found a low prevalence of E. canis (1.8\%) in 54 dogs in the north [58].

Conversely, in dogs showing clinical signs consistent with babesiosis, the pathogen is often detected both by blood smear examination and PCR $[60,61]$. In north Italy, Babesia canis was found by PCR in 30/103 sick dogs $(29 \%)$ and B. vogeli in 1/103 (0.9 \%) [61]. However, $55 \%$ of the dogs infected by B. canis had travelled in eastern Europe, where babesiosis and the tick vector Dermacentor reticulatus are endemic [62], and were therefore likely to be imported cases.

The comparable rate of exposure to pathogens transmitted by ticks and sandflies in CBDs and FRDs was unexpected considering that CBD owners are very careful about their dogs' health, including the control of ectoparasites and prevention of dirofilariosis. Conversely, less or no care was expected to be taken of FRDs. This assumption is strengthened by the fact that positivity for filariae was found exclusively in FRDs, while the owners of CBDs proved to correctly use prophylactic measures

Table 5 Distribution of antibody titres for each pathogen in candidate blood donors and free-roaming dogs in northeast Italy, 2014-2015

\begin{tabular}{|c|c|c|c|c|c|c|c|c|}
\hline \multirow[t]{2}{*}{ Pathogens $^{a}$} & \multicolumn{4}{|c|}{ Candidate blood donors } & \multicolumn{4}{|c|}{ Free-roaming dogs } \\
\hline & Pos $1^{\text {st }}$ dilution & Pos $2^{\text {nd }}$ dilution & Pos $>2^{\text {nd }}$ dilution & $\overline{\text { Max. titre }}$ & Pos $1^{\text {st }}$ dilution & Pos $2^{\text {nd }}$ dilution & Pos $>2^{\text {nd }}$ dilution & Max. titre \\
\hline $\begin{array}{l}\text { Anaplasma } \\
\text { phagocytophilum }\end{array}$ & 5 & 2 & 0 & $1: 160$ & 5 & 3 & 3 & $1: 5120$ \\
\hline Babesia canis & 0 & 0 & 0 & - & 3 & 0 & 0 & $1: 16$ \\
\hline Ehrlichia canis & 1 & 1 & 0 & 1:100 & 7 & 1 & 1 & 1:400 \\
\hline $\begin{array}{l}\text { Leishmania } \\
\text { infantum }\end{array}$ & 8 & 1 & 1 & $1: 1280$ & 24 & 0 & 0 & $1: 40$ \\
\hline Rickettsia conorii & 14 & 4 & 6 & $1: 8192$ & 33 & 19 & 20 & $1: 2048$ \\
\hline Rickettsia rickettsii & 7 & 1 & 4 & $1: 2048$ & 22 & 9 & 17 & $1: 2048$ \\
\hline
\end{tabular}

${ }^{a}$ Serum screening dilution: $A p$ (1:80); BC (1:16); Ec (1:50); Li (1:40); Rc (1:64); Rr (1:64) 
Table 6 Breed, age, gender and location of the dogs according to seropositivity

\begin{tabular}{|c|c|c|c|c|c|c|}
\hline Data & $\begin{array}{l}\text { A. phagocythophilum } \\
\text { pos/tested (\%) }\end{array}$ & $\begin{array}{l}\text { B. canis } \\
\text { pos/tested (\%) }\end{array}$ & $\begin{array}{l}\text { E. canis } \\
\text { pos/tested (\%) }\end{array}$ & $\begin{array}{l}\text { L. infantum } \\
\text { pos/tested (\%) }\end{array}$ & $\begin{array}{l}\text { R. conorii } \\
\text { pos/tested (\%) }\end{array}$ & $\begin{array}{l}\text { R. rickettsii } \\
\text { pos/tested (\%) }\end{array}$ \\
\hline \multicolumn{7}{|l|}{ Breed } \\
\hline crossbreed & 10/327 (3.1) & $3 / 323(0.9)$ & 9/327 (2.8) & 23/327 (7.0) & 68/327 (20.8) & 46/323 (14.2) \\
\hline other breed & 7/153 (4.6) & $0 / 111(0)$ & $2 / 153(1.3)$ & $11 / 153(7.2)$ & 25/153 (16.3) & 13/116 (11.2) \\
\hline \multicolumn{7}{|l|}{ Age (months) } \\
\hline$\leq 12$ & 2/91 (2.2) & 1/91 (1.1) & $1 / 91(1.1)$ & 9/91 (9.9) & 16/91 (17.6) & 10/91 (11.0) \\
\hline$>12 \leq 36$ & $5 / 88(5.7)$ & $1 / 72(1.4)$ & 0/87 (0) & $11 / 87(12.6)$ & 15/87 (17.2) & $7 / 74(9.5)$ \\
\hline$>36 \leq 60$ & $3 / 69(4.3)$ & $1 / 59(1.7)$ & $1 / 70(1.4)$ & $3 / 69(4.3)$ & $9 / 69$ (13.0) & 8/59 (13.6) \\
\hline$>60$ & 4/68 (5.9) & 0/61 (0) & 0/69 (0) & $2 / 69(2.9)$ & 14/69 (20.3) & $14 / 63(22.2)$ \\
\hline \multicolumn{7}{|l|}{ Gender } \\
\hline female & 11/177 (6.2) & $1 / 148(0.7)$ & $3 / 177(1.7)$ & $13 / 176(7.4)$ & $30 / 176(17.0)$ & $16 / 150(10.7)$ \\
\hline male & 6/303 (2.0) & $2 / 286(0.7)$ & $8 / 304(2.6)$ & $21 / 304(6.9)$ & $64 / 304(21.1)$ & $44 / 289(15.2)$ \\
\hline \multicolumn{7}{|l|}{ Location } \\
\hline Padua & $9 / 226(4.0)$ & $3 / 225(1.3)$ & 2/228 (0.9) & $16 / 226(7.1)$ & $41 / 227(18.1)$ & $34 / 223(15.2)$ \\
\hline Treviso & 2/157 (1.3) & 0/140 (0) & $7 / 158(4.4)$ & 10/157 (6.4) & $39 / 157$ (24.8) & 18/140 (12.9) \\
\hline Venice & $3 / 59(5,1)$ & 0/43 (0) & 0/59 (0) & 4/59 (6.8) & 8/59 (13.6) & $5 / 48(10.4)$ \\
\hline Other & 4/46 (8.7) & 0/34 (0) & $2 / 46(4.3)$ & $4 / 46(8.7)$ & $8 / 46(17.4)$ & 3/34 (8.8) \\
\hline
\end{tabular}

against dirofilariosis. The similar seroprevalence for VBPs in the two groups may be explained by limited or incorrect use of compounds with repellent activity against arthropod vectors, as demonstrated by the results of a questionnaire administered to dog and cat owners in Portugal [63]. Repellents have in fact been proven to prevent vector bites and consequently the transmission of pathogens, even in highly endemic areas of south Italy [47, 64-66].

Our results confirm that serological positivity against tickborne pathogens, even with very high titres, has to be carefully considered. Clinical observations, sensitive PCRs and repeated serological tests must be applied to confirm acute or chronic infections caused by rickettsial agents [41]. In addition, more specific, commercially available serological rickettsial assays, coupled with deeper knowledge of the pathogenic potential of the different species, are greatly required.

Although exposure to VBPs is frequent for dogs living in northeast Italy, our results suggest that the risk of transmission by blood transfusion is low, if donors are carefully selected. Specifically, in areas endemic for Ixodes spp., it may be difficult to identify donors that are seronegative for Anaplasma spp. and Rickettsia spp. It might, therefore, be acceptable to use seropositive but PCR negative dogs as donors in such situations [67]. Conversely, serological screening for $E$. canis and $L$. infantum remains mandatory, since the antibody titres are predictive of infection. Finally, the diffusion and prevalence of other pathogens, such as Bartonella and haemoplasmas, should be investigated, as recommended by the updated Consensus Statements of the American College of Veterinary Internal Medicine (ACVIM) [67].

\section{Conclusions}

This study has improved our knowledge on the circulation of important VBPs in northeast Italy and has demonstrated a considerable rate of exposure to VBPs among dog populations. Although owners of CBDs reported regularly using compounds against fleas and ticks, their dogs had similar exposure to vector-borne pathogens as free-roaming dogs. This prompts the need to improve owner education on the use of repellent compounds in order to prevent arthropod bites and, consequently, the transmission of VBPs. The seroreactivity of CBDs to all the screened VBPs reinforces the need to continue applying this panel of PCRs at each blood donation. The test panel should also be continually revised according to additional information gathered on the introduction of pathogens and/or vectors from endemic areas.

\section{Abbreviations}

VBP, vector-borne pathogen; $C B D$, candidate blood donors; FRD, freeroaming dogs; ACVIM, American College of Veterinary Internal Medicine; PCR, polymerase chain reaction; EDTA, Ethylene Diamine Tetraacetic Acid; DNA, Deoxyribonucleic acid; rRNA, ribosomal ribonucleic acid; IFA, Immunofluorescence Assay.

\section{Acknowledgments}

The authors are grateful to Alberto Camerini, Riccardo Friso, Alfio Bortolini, Aldo Costa and Giovanni Dal Maso of the Local Veterinary Units for their help in the recruitment of dogs and sampling. The authors are very grateful to the owners of the dogs for their contribution to canine blood donation. The authors wish to thank Joanne Fleming for the English language revision.

\section{Funding}

This work was supported by an Italian Ministry of Health grant (project code RC-IZSVE 03/2013).

The publication of the paper has been sponsored by Bayer Animal Health in the framework of the 11th CVBD World Forum Symposium. 


\section{Availability of data and materials}

Data supporting the conclusions of this article are included within the article.

\section{Authors' contribution}

MV and GC conceived the study and wrote the paper; MV and AC performed the sampling and clinical evaluation of the dogs; EC performed the blood smear examinations, SR, GDR and SC performed the biomolecular screening, and AN and LL the serological screening; DO revised the paper and contributed to the background and discussion. All the authors revised and approved the MS

\section{Competing interests}

The authors declare that they have no competing interests.

\section{Consent for publication}

Not applicable

\section{Ethical approval and consent to participate}

All samples were collected by professional vets in veterinary facilities and used with the owner consent (CBDs) or collected by the Local Veterinary Health Unit (FRDs). The study did not involve any experimental work, therefore no ethical committee approval was required.

\section{Author details}

'Istituto Zooprofilattico Sperimentale delle Venezie, Legnaro, Padova, Italy. ${ }^{2}$ Dipartimento di Medicina Veterinaria, Università degli Studi di Bari, Valenzano, Italy.

\section{Received: 14 March 2016 Accepted: 10 June 2016}

\section{Published online: 29 June 2016}

\section{References}

1. Solano-Gallego L, Trotta M, Razia L, Furlanello T, Caldin M. Molecular survey of Ehrlichia canis and Anaplasma phagocytophilum from blood of dogs in Italy. Ann N Y Acad Sci. 2006;1078:515-8.

2. Solano-Gallego L, Trotta M, Caldin M, Furlanello T. Molecular survey of Rickettsia spp. in sick dogs in Italy. Zoonoses Public Health. 2008;55(8-10): 521-5.

3. Iori A, Gabrielli S, Calderini P, Moretti A, Pietrobelli M, Tampieri MP, Galupp $\mathrm{R}$, Cancrini G. Tick reservoirs for piroplasms in central and northern Italy. Vet Parasitol. 2010;170(3-4):291-6.

4. Maroli M, Rossi L, Baldelli R, Capelli G, Ferroglio E, Genchi C, et al. The northward spread of leishmaniasis in Italy: evidence from retrospective and ongoing studies on the canine reservoir and phlebotomine vectors. Trop Med Int Health. 2008;13(2):256-64.

5. Otranto D, Capelli G, Genchi C. Changing distribution patterns of canine vector borne diseases in Italy: leishmaniosis vs. dirofilariosis. Parasit Vectors. 2009;2 Suppl 1:S2

6. Otranto D, Dantas-Torres F. Canine and feline vector-borne diseases in Italy: current situation and perspectives. Parasit Vectors. 2010;3:2.

7. Capelli G, Frangipane di Regalbono A, Simonato G, Cassini R, Cazzin S, Cancrini $\mathrm{G}$, et al. Risk of canine and human exposure to Dirofilaria immitis infected mosquitoes in endemic areas of Italy. Parasit Vectors. 2013;6:60.

8. Mulatti P, Bonfanti L, Capelli G, Capello K, Lorenzetto M, Terregino C, et al. West Nile virus in north-eastern Italy, 2011: entomological and equine IgMbased surveillance to detect active virus circulation. Zoonoses Public Health. 2013;60(5):375-82.

9. Calzolari M, Pautasso A, Montarsi F, Albieri A, Bellini R, Bonilauri P, et al. West Nile virus surveillance in 2013 via mosquito screening in northern Italy and the influence of weather on virus circulation. PLoS One. 2015;10(10): e0140915.

10. Gobbi F, Capelli G, Angheben A, Giobbia M, Conforto M, Franzetti M, et al. Human and entomological surveillance of West Nile fever, dengue and chikungunya in Veneto Region, Italy, 2010-2012. BMC Infect Dis. 2014;14:60.

11. Grisenti M, Vázquez A, Herrero L, Cuevas L, Perez-Pastrana E, Arnoldi D, et al. Wide detection of Aedes flavivirus in north-eastern Italy-a European hotspot of emerging mosquito-borne diseases. J Gen Virol. 2015;96(Pt 2):420-30.

12. Capelli G, Drago A, Martini S, Montarsi F, Soppelsa M, Delai N, et al. First report in Italy of the exotic mosquito species Aedes (Finlaya) koreicus, a potential vector of arboviruses and filariae. Parasit Vectors. 2011;4:188.
13. Montarsi F, Drago A, Martini S, Calzolari M, De Filippo F, Bianchi A, et al. Current distribution of the invasive mosquito species, Aedes koreicus [Hulecoeteomyia koreica] in northern Italy. Parasit Vectors. 2015;8:614.

14. Marcantonio M, Metz M, Baldacchino F, Arnoldi D, Montarsi F, Capelli G, et al. First assessment of potential distribution and dispersal capacity of the emerging invasive mosquito Aedes koreicus in Northeast Italy. Parasit Vectors. 2016;9(1):63.

15. Cancrini G, Frangipane di Regalbono A, Ricci I, Tessarin C, Gabrielli S, Pietrobelli M. Aedes albopictus is a natural vector of Dirofilaria immitis in Italy. Vet Parasitol. 2003;118(3-4):195-202.

16. Cancrini G, Romi R, Gabrielli S, Toma L, DI Paolo M, Scaramozzino P. First finding of Dirofilaria repens in a natural population of Aedes albopictus. MedVet Entomol. 2003:17(4):448-51.

17. Latrofa MS, Montarsi F, Ciocchetta S, Annoscia G, Dantas-Torres F, Ravagnan S, et al. Molecular xenomonitoring of Dirofilaria immitis and Dirofilaria repens in mosquitoes from north-eastern Italy by real-time PCR coupled with melting curve analysis. Parasit Vectors. 2012;5:76.

18. Montarsi F, Ciocchetta S, Devine G, Ravagnan S, Mutinelli F, Frangipane di Regalbono A, et al. Development of Dirofilaria immitis within the mosquito Aedes (Finlaya) koreicus, a new invasive species for Europe. Parasit Vectors. 2015;8:177.

19. Beninati T, Lo N, Noda H, Esposito F, Rizzoli A, Favia G, Genchi C. First detection of spotted fever group Rickettsiae in Ixodes ricinus from Italy. Emerg Infect Dis. 2002;8:983-6.

20. Floris R, Yurtman AN, Margoni EF, Mignozzi K, Boemo B, Altobelli A, Cinco M. Detection and identification of Rickettsia species in the northeast of Italy. Vector Borne Zoonotic Dis. 2008;8:777-82

21. Cassini R, Zanutto S, Frangipane di Regalbono A, Gabrielli S, Calderini P, Moretti A, et al. Canine piroplasmosis in Italy: epidemiological aspects in vertebrate and invertebrate hosts. Vet Parasitol. 2009:165(1-2):30-5.

22. Nazzi F, Martinelli E, Del Fabbro S, Bernardinelli I, Milani N, lob A, et al. Ticks and Lyme borreliosis in an alpine area in northeast Italy. Med Vet Entomol. 2010;24(3):220-6.

23. Tagliapietra V, Rosà R, Arnoldi D, Cagnacci F, Capelli G, Montarsi F, et al. Saturation deficit and deer density affect questing activity and local abundance of Ixodes ricinus (Acari, Ixodidae) in Italy. Vet Parasitol. 2011;183(1-2):114-24

24. Capelli G, Ravagnan S, Montarsi F, Ciocchetta S, Cazzin S, Porcellato E, et al. Occurrence and identification of risk areas of Ixodes ricinus-borne pathogens: a cost-effectiveness analysis in north-eastern Italy. Parasit Vectors. 2012;5:61.

25. Trotta M, Nicetto M, Fogliazza A, Montarsi F, Caldin M, Furlanello T, et al. Detection of Leishmania infantum, Babesia canis, and Rickettsiae in ticks removed from dogs living in Italy. Ticks Tick Borne Dis. 2012;3(5-6):294-7.

26. Baráková I, Derdáková M, Carpi G, Rosso F, Collini M, Tagliapietra V, et al. Genetic and ecologic variability among Anaplasma phagocytophilum strains, northern Italy. Emerg Infect Dis. 2014;20(6):1082-5.

27. Morosetti G, Bongiorno G, Beran B, Scalone A, Moser J, Gramiccia M, et al. Risk assessment for canine leishmaniasis spreading in the north of Italy. Geospat Health. 2009;4(1):115-27.

28. Signorini M, Cassini R, Drigo M, Frangipane di Regalbono A, Pietrobelli M, Montarsi F, Stensgaard AS. Ecological niche model of Phlebotomus perniciosus, the main vector of canine leishmaniasis in north-eastern Italy. Geospat Health. 2014;9(1):193-201.

29. Wardrop KJ, Reine N, Birkenheuer A, Hale A, Hohenhaus A, Crawford C, Lappin MR. Canine and feline blood donor screening for infectious disease. J Vet Intern Med. 2005;19(1):135-42

30. OIE/WHO. Manual of diagnostic tests and vaccines for terrestrial animals 2014. Chapter 2.1.8. (available at: http://www.oie.int/international-standardsetting/terrestrial-manual/access-online/)

31. Casati S, Sager H, Gern L, Piffaretti JC. Presence of potentially pathogenic Babesia sp. for human in Ixodes ricinus in Switzerland. Ann Agric Environ Med. 2006;13:65-70

32. Choi YJ, Jang WJ, Kim JH, Ryu JS, Lee SH, Park KH, et al. Spotted fever group and Typhus Group Rickettsioses in Humans, South Korea. Emerg Infect dDis. 2005:11- N²:237-44.

33. Sharief AH, Khalil E-TAG, Barker DC, Omer SA, Abdalla HS, Ibrahim ME. Simple and direct characterization of Leishmania donovani isolates based on cytochrome oxidase II gene sequences. Open Trop Med J. 2011;4:1-5.

34. Nazari M, Lim SY, Watanabe M, Sharma RSK. Molecular detection of Ehrlichia canis in dogs in Malaysia. PLoS Negl Trop Dis. 2013;7:e1982. 
35. Massung RF, Slater KG. Comparison of PCR assays for detection of the agent of human granulocytic ehrlichiosis, Anaplasma phagocytophilum. J Clin Microbiol. 2003;41(2):717-22.

36. Smith J, McElhinney LM, Heaton PR, Black ER, Lowings JP. Assessment of template quality by the incorporation of an internal control into a RT-PCR for the detection of rabies and rabies-related viruses. J Virol Methods. 2000;4:107-15.

37. Euzeby J. Diagnostic expérimental des helminthoses animals (animaux domestiques, animaux de laboratoire, primates): travaux pratiques d'helmenthologie vétérinaire/Jacques Euzeby, J., Livre 1: Généralites, diagnostic ante mortem. IXth ed. Paris: Informations Techniques des Services Vétérinaires; 1981. p. 349.

38. Latrofa MS, Dantas-Torres F, Annoscia G, Genchi M, Traversa D, Otranto D. A duplex real-time polymerase chain reaction assay for the detection of and differentiation between Dirofilaria immitis and Dirofilaria repens in dogs and mosquitoes. Vet Parasitol. 2012;185(2-4):181-5.

39. Viera JA, Garrett MJ. Understanding interobserver agreement: The Kappa statistic. Fam Med. 2005;37(5):360-3

40. Solano-Gallego L, Caprì A, Pennisi MG, Caldin M, Furlanello T, Trotta M. Acute febrile illness is associated with Rickettsia spp. infection in dogs. Parasit Vectors. 2015:8:216.

41. Maioli G, Pistone D, Bonilauri P, Pajoro M, Barbieri I, Mulatto P, et al. Etiological agents of rickettsiosis and anaplasmosis in ticks collected in Emilia-Romagna region (Italy) during 2008 and 2009. Exp Appl Acarol. 2012; 57(2):199-208

42. Chisu V, Masala G, Foxi C, Socolovschi C, Raoult D, Parola P. Rickettsia conorii israelensis in Rhipicephalus sanguineus ticks, Sardinia, Italy. Ticks Tick Borne Dis. 2014;5(4):446-8.

43. Mancini F, Ciccozzi M, Lo Presti A, Cella E, Giovanetti M, Di Luca M, et al. Characterization of spotted fever group Rickettsiae in ticks from a city park of Rome, Italy. Ann Ist Super Sanita. 2015;51(4):284-90.

44. Ciceroni L, Pinto A, Ciarrocchi S, Ciervo A. Current knowledge of rickettsial diseases in Italy. Ann N Y Acad Sci. 2006;1078:143-9.

45. Kohn B, Silaghi C, Galke D, Arndt G, Pfister K. Infections with Anaplasma phagocytophilum in dogs in Germany. Res Vet Sci. 2011;91(1):71-6.

46. Ebani W, Bertelloni F, Torracca B, Cerri D. Serological survey of Borrelia burgdorferi sensu lato, Anaplasma phagocytophilum, and Ehrlichia canis infections in rural and urban dogs in Central Italy. Ann Agric Environ Med. 2014;21(4):671-5

47. Otranto D, Paradies P, Testini G, Latrofa MS, Weigl S, Cantacessi C, et al. Application of $10 \%$ imidacloprid/50 \% permethrin to prevent Ehrlichia canis exposure in dogs under natural conditions. Vet Parasitol. 2008;153(3-4):320-8.

48. Pennisi MG, Caprì A, Solano-Gallego L, Lombardo G, Torina A, Masucci M. Prevalence of antibodies against Rickettsia conorii, Babesia canis, Ehrlichia canis, and Anaplasma phagocytophilum antigens in dogs from the Stretto di Messina area (Italy). Ticks Tick Borne Dis. 2012;3(5-6):315-8.

49. Gray J, Dantas-Torres F, Estrada-Peña A, Levin M. Systematics and ecology of the brown dog tick, Rhipicephalus sanguineus. Ticks Tick Borne Dis. 2013;4(3):171-80.

50. Dantas-Torres F, Otranto D. Further thoughts on the taxonomy and vector role of Rhipicephalus sanguineus group ticks. Vet Parasitol. 2015;208(1-2):9-13.

51. Solano-Gallego L, Koutinas A, Miró G, Cardoso L, Pennisi MG, Ferrer L, et al. Directions for the diagnosis, clinical staging, treatment and prevention of canine leishmaniosis. Vet Parasitol. 2009;165(1-2):1-18.

52. Mettler M, Grimm F, Capelli G, Camp H, Deplazes P. Evaluation of enzymelinked immunosorbent assays, an immunofluorescent-antibody test, and two rapid tests (immunochromatographic-dipstick and gel tests) for serological diagnosis of symptomatic and asymptomatic Leishmania infections in dogs. J Clin Microbiol. 2005;43(11):5515-9.

53. Solano-Gallego L, Villanueva-Saz S, Carbonell M, Trotta M, Furlanello T, Natale A. Serological diagnosis of canine leishmaniosis: comparison of three commercial ELISA tests (Leiscan, ID Screen and Leishmania 96), a rapid test (Speed Leish K) and an in-house IFAT. Parasit Vectors. 2014;7:111.

54. Ferroglio E, Romano A, Passera S, D'Angelo A, Guiso P, Ghiggi E, et al. Dogs' parasite and zoonotic risk: from old to new "emergencies" in the North-West of Italy. Parassitologia. 2006:48(1-2):115-6.

55. Cassini R, Signorini M, Frangipane di Regalbono A, Natale A, Montarsi F, Zanaica $M$, et al. Preliminary study of the effects of preventive measures on the prevalence of Canine Leishmaniosis in a recently established focus in northern Italy. Vet Ital. 2013:49(2):157-61.
56. Genchi C, Kramer LH, Prieto G. Epidemiology of canine and feline dirofilariasis, a global view. In: Simón F, Genchi C, editors. Heartworm Infection in Humans and Animals. Salamanca: Ediciones Universidad de Salamanca; 2001:121-134.

57. Capelli G, Poglayen G, Bertotti F, Giupponi S, Martini M. The host-parasite relationship in canine heartworm infection in a hyperendemic area of Italy. Vet Res Commun. 1996;20(4):320-30.

58. Otranto D, Testini G, Dantas-Torres F, Latrofa MS, Diniz PP, de Caprariis D, et al. Diagnosis of canine vector-borne diseases in young dogs: a longitudinal study. J Clin Microbiol. 2010;48(9):3316-24.

59. de Caprariis D, Dantas-Torres F, Capelli G, Mencke N, Stanneck D, Breitschwerdt EB, et al. Evolution of clinical, haematological and biochemical findings in young dogs naturally infected by vector-borne pathogens. Vet Microbiol. 2011;149(1-2):206-12.

60. Solano-Gallego L, Trotta M, Carli E, Carcy B, Caldin M, Furlanello T. Babesia canis canis and Babesia canis vogeli clinicopathological findings and DNA detection by means of PCR-RFLP in blood from Italian dogs suspected of tick-borne disease. Vet Parasitol. 2008;157(3-4):211-21.

61. Trotta M, Fogliazza A, Furlanello T, Solano-Gallego L. A molecular and serological study of exposure to tick-borne pathogens in sick dogs from Italy. Clin Microbiol Infect. 2009;15 Suppl 2:62-3.

62. Rubel F, Brugger K, Pfeffer M, Chitimia-Dobler L, Didyk YM, Leverenz S, et al. Geographical distribution of Dermacentor marginatus and Dermacentor reticulatus in Europe. Ticks Tick Borne Dis. 2016:7(1):224-33.

63. Matos M, Alho AM, Owen SP, Nunes T, Madeira de Carvalho L. Parasite control practices and public perception of parasitic diseases: A survey of dog and cat owners. Prev Vet Med. 2015;122(1-2):174-80.

64. Otranto D, Paradies P, Lia RP, Latrofa MS, Testini G, Cantacessi C, et al. Efficacy of a combination of $10 \%$ imidacloprid/50 \% permethrin for the prevention of leishmaniasis in kennelled dogs in an endemic area. Vet Parasitol. 2007:144(3-4):270-8.

65. Otranto D, Dantas-Torres F, de Caprariis D, Di Paola G, Tarallo VD, Latrofa MS, et al. Prevention of canine leishmaniosis in a hyper-endemic area using a combination of $10 \%$ imidacloprid/4.5 \% flumethrin. PLoS One. 2013;8(2): e56374.

66. Brianti E, Gaglio G, Napoli E, Falsone L, Prudente C, Solari Basano F, et al. Efficacy of a slow-release imidacloprid (10 \%)/flumethrin (4.5\%) collar for the prevention of canine leishmaniosis. Parasit Vectors. 2014;7:327.

67. Wardrop KJ, Birkenheuer A, Blais MC, Callan MB, Kohn B, Lappin MR, Sykes J. Update on canine and feline blood donor screening for blood-borne pathogens. Vet Intern Med. 2016;30(1):15-35.

\section{Submit your next manuscript to BioMed Central and we will help you at every step:}

- We accept pre-submission inquiries

- Our selector tool helps you to find the most relevant journal

- We provide round the clock customer support

- Convenient online submission

- Thorough peer review

- Inclusion in PubMed and all major indexing services

- Maximum visibility for your research

Submit your manuscript at www.biomedcentral.com/submit 